\title{
Asparagine reduces the mRNA expression of muscle atrophy markers via regulating protein kinase B (Akt), AMP-activated protein kinase $\alpha$, toll-like receptor 4 and nucleotide-binding oligomerisation domain protein signalling in weaning piglets after lipopolysaccharide challenge
}

\author{
Xiuying Wang ${ }^{1}$, Yulan Liu ${ }^{1}$, Shuhui Wang ${ }^{1}$, Dingan $\mathrm{Pi}^{1}$, Weibo Leng ${ }^{1}$, Huiling Zhu ${ }^{1}$, Jing Zhang ${ }^{1}$, \\ Haifeng Shi ${ }^{1}$, Shuang $\mathrm{Li}^{1}$, Xi Lin $^{2}$ and Jack Odle ${ }^{2}$ \\ ${ }^{1}$ Hubei Key Laboratory of Animal Nutrition and Feed Science, Hubei Collaborative Innovation Center for Animal Nutrition \\ and Feed Safety, Wuban Polytechnic University, Wuban 430023, People's Republic of China \\ ${ }^{2}$ Laboratory of Developmental Nutrition, Department of Animal Science, North Carolina State University, Raleigh, \\ NC 27695, USA \\ (Submitted 16 November 2015 - Final revision received 22 June 2016 - Accepted 27 June 2016 - First published online 30 August 2016)
}

\begin{abstract}
Pro-inflammatory cytokines are critical in mechanisms of muscle atrophy. In addition, asparagine (Asn) is necessary for protein synthesis in mammalian cells. We hypothesised that Asn could attenuate lipopolysaccharide (LPS)-induced muscle atrophy in a piglet model. Piglets were allotted to four treatments (non-challenged control, LPS-challenged control, LPS + 0.5\% Asn and LPS + 1.0\% Asn). On day 21, the piglets were injected with LPS or saline. At $4 \mathrm{~h}$ post injection, piglet blood and muscle samples were collected. Asn increased protein and RNA content in muscles, and decreased mRNA expression of muscle atrophy F-box (MAFbx) and muscle RING finger 1 (MuRF1). However, Asn had no effect on the protein abundance of MAFbx and MuRF1. In addition, Asn decreased muscle AMP-activated protein kinase (AMPK) $\alpha$ phosphorylation, but increased muscle protein kinase B (Akt) and Forkhead Box O (FOXO) 1 phosphorylation. Moreover, Asn decreased the concentrations of TNF- $\alpha$, cortisol and glucagon in plasma, and TNF- $\alpha$ mRNA expression in muscles. Finally, Asn decreased mRNA abundance of muscle toll-like receptor (TLR) 4 and nucleotide-binding oligomerisation domain protein (NOD) signalling-related genes, and regulated their negative regulators. The beneficial effects of Asn on muscle atrophy may be associated with the following: (1) inhibiting muscle protein degradation via activating Akt and inactivating AMPK $\alpha$ and FOXO1; and (2) decreasing the expression of muscle pro-inflammatory cytokines via inhibiting TLR4 and NOD signalling pathways by modulation of their negative regulators.
\end{abstract}

Key words: Asparagine: Lipopolysaccharides: Muscle atrophy: Pro-inflammatory cytokines

Skeletal muscle, the most widely distributed and rapidly growing tissue of the vertebrate body, plays major roles in different biological functions ${ }^{(1)}$. However, infection and inflammation results in the rapid loss of muscle mass and myofibrillar proteins (muscle atrophy), which results in muscle weakness and increased morbidity during acute illness or poor quality of life ${ }^{(1,2)}$. Multiple lines of evidence suggest that pro-inflammatory cytokines may contribute to muscle atrophy ${ }^{(3,4)}$. Pro-inflammatory cytokines, such as IL- $1 \beta$, IL- 6 and TNF- $\alpha$, have been implicated in the regulation of muscle protein degradation ${ }^{(5)}$. In addition, proinflammatory cytokines are also responsible for increased muscle atrophy F-box (MAFbx) and muscle RING finger 1 (MuRF1) expression $^{(1)}$, which are considered as accurate markers of the atrophy process ${ }^{(6)}$. Thus, nutritional regulation targeting the suppression of pro-inflammatory cytokine expression may hold great promise for attenuating muscle atrophy and improving health of animals and humans.

Asparagine (Asn), a neutral amino acid, can be synthesised from aspartate and glutamine ${ }^{(7)}$. Thus, traditionally, it is thought as a nutritionally non-essential amino acid in mammals ${ }^{(7)}$. However, increasing evidence has shown that Asn plays an important role in many physiological and biological processes. First, Asn is necessary for the synthesis of many proteins in mammalian cells ${ }^{(8)}$. In addition, Asn has evolved to be

Abbreviations: Akt, protein kinase B; AMPK, AMP-activated protein kinase; Asn, asparagine; CENTB1, centaurin $\beta 1$; CONTR, non-challenged control; FOXO, Forkhead Box O; GAPDH, glyceraldehyde 3-phosphate dehydrogenase; LD, longissimus dorsi; LPS, lipopolysaccharide; MAFbx, muscle atrophy F-box; MuRF1, muscle RING finger 1; MyD88, myeloid differentiation factor 88; NOD, nucleotide-binding oligomerisation domain protein; pAkt, phosphorylated Akt; pAMPK $\alpha$, phosphorylated AMPK $\alpha$; RP105, radioprotective 105; SOCS1, suppressor of cytokine signalling 1; tAkt, total Akt; tAMPK $\alpha$, total AMPK $\alpha$; tFOXO1, total FOXO 1; TLR, toll-like receptor; Tollip, toll-interacting protein.

* Corresponding author: Y. Liu, fax +86278395 6175, email yulanflower@126.com 
a metabolic regulator of cell proliferation and apoptosis ${ }^{(8)}$. Moreover, through the reaction catalysed by asparginase, Asn can be degraded into aspartate, which is a precursor for gluconeogenesis or tricarboxylic acid cycle $^{(9)}$. Of particular interest, Lancha et $a l .{ }^{(10)}$ reported that Asn and aspartate could be metabolised by skeletal muscle. They have demonstrated that Asn and aspartate supplementation increased glycogen concentration and modulated the glucose uptake in muscle ${ }^{(10)}$. However, to our knowledge, the research on Asn modulating muscle atrophy and its mechanism(s) are lacking.

Pattern-recognition receptors, including toll-like receptor (TLR) and nucleotide-binding oligomerisation domain protein (NOD), activate downstream signalling pathways that induce innate immune responses via recognising pathogen-associated molecular patterns ${ }^{(11)}$. Several lines of evidence indicate that TLR and NOD are functionally expressed in skeletal muscles ${ }^{(4,12)}$. Both TLR and NOD mediate the activation of NF- $\kappa \mathrm{B}$ pathway, which induces the expression of pro-inflammatory cytokines, such as IL- $1 \beta$, IL- 6 and TNF- $\alpha^{(13)}$. These pro-inflammatory cytokines are critical regulators of muscle protein balance ${ }^{(14)}$. In addition, the pro-inflammatory cytokines have been demonstrated to affect protein kinase B (Akt) ${ }^{(15)}$ and AMP-activated protein kinase (AMPK) pathways ${ }^{(16,17)}$. The activation of Akt and AMPK regulate muscle protein degradation through the nuclear transcription factors termed Forkhead Box O (FOXO) and FOXO target genes (i.e. MAFbx and MuRF1) ${ }^{(1,18)}$.

On the basis of the findings cited above, we hypothesised that Asn supplementation would suppress the production of muscle pro-inflammatory cytokines through influencing TLR4 and NOD signalling pathways, and protect against muscle atrophy, partially via regulating Akt and AMPK signalling. In this study, administration of Escherichia coli lipopolysaccharide (LPS) to animals was used to mimic endotoxaemia ${ }^{(15)}$. Besides, we used a piglet model, which is a well-characterised animal model for nutrition research of humans, specifically children and adolescents with rapid muscle growth ${ }^{(19,20)}$. The aim of this experiment was to investigate whether Asn could attenuate muscle atrophy caused by LPS challenge, and to elaborate its molecular mechanism(s).

\section{Methods}

\section{Animal care and experimental design}

This study was approved by the Animal Care and Use Committee of Hubei Province, People's Republic of China. A total of twenty-four weaned castrated barrows (Duroc $\times$ Large White $\times$ Landrace, 8.9 (SEM 0.7) kg initial body weight (BW)) were acquired and randomly divided into four treatments. There were six replicate pens per treatment. To keep animal uniformity, the piglets were of the same sex. The piglet was individually caged in $1.80 \times 1.10 \mathrm{~m}$ pen with a feeder and a nipple waterer, and housed in a controlled-environment chamber. The basal diet (online Supplementary Table S1) was prepared according to the nutrient requirements of the National Research Council ${ }^{(21)}$.

The experiment consisted of four treatment groups: (1) nonchallenged control (CONTR; piglets fed a control diet and injected with $0.9 \% \mathrm{NaCl}$ solution); (2) LPS-challenged control (LPS; piglets fed the same control diet and injected with $E$. coli LPS (Escherichia coli serotype 055: B5; Sigma Chemical Inc.)); (3) LPS $+0.5 \%$ Asn treatment (piglets fed a $0.5 \%$ Asn diet and injected with LPS); and (4) LPS $+1.0 \%$ Asn treatment (piglets fed a $1.0 \%$ Asn diet and injected with LPS). The Asn doses (purity >99\%; Amino Acid Bio-Chemical Co.) were selected according to our previous studies ${ }^{(22)}$. Our previous studies showed that, before LPS challenge 0.5 and $1.0 \%$ Asn addition did not affect growth performance, total and differential leucocyte counts and serum biochemical parameters of weaning piglets (Xiuying Wang, Yulan Liu, Dingan Pi, Weibo Leng, Huiling Zhu, Shuang Li and Haifeng Shi, unpublished results), indicating that the Asn level in basal diet was enough to meet the requirements of weanling piglets' growth and physiological function in normal physiological condition. However, our previous studies also showed that, after LPS challenge, $0.5 \%$ Asn attenuated weight loss, and both 0.5 and $1.0 \%$ Asn attenuated the changes of total and differential leucocyte counts and serum biochemical parameters induced by LPS in weaning piglets ${ }^{(22)}$, suggesting the importance of exogenous Asn supply under pathological conditions. Thus, in the current experiment, we focused on investigating the effect of dietary 0.5 and $1.0 \%$ Asn supplementation on muscle variables in LPS-challenged pigs, and did not investigate the effect of Asn in pigs without LPS challenge. We added 1.35, 0.68 and $0 \%$ alanine (purity >99\%; Amino Acid Bio-Chemical Co.) to the control, $0.5 \%$ Asn and $1.0 \%$ Asn diets, respectively, to get isonitrogenous diets. After 19-d feeding with the control, $0.5 \%$ Asn and $1.0 \%$ Asn diets, the challenged groups were treated with intraperitoneal injection of LPS at $100 \mu \mathrm{g} / \mathrm{kg} \mathrm{BW}$, and the nonchallenged group was treated with the same volume of $0.9 \%$ $\mathrm{NaCl}$ solution. The LPS dose was chosen in accordance with our previous experiments ${ }^{(23,24)}$, which demonstrated that this dose of LPS caused tissue damage in weaning piglets.

\section{Plasma and muscle sample collections}

At $4 \mathrm{~h}$ after administration with saline or LPS, blood samples were collected into heparinised vacuum tubes and centrifuged (3500 $\mathrm{g}$ for $10 \mathrm{~min}$ ) to separate plasma. Plasma was kept at $-80^{\circ} \mathrm{C}$ for further measurement of TNF- $\alpha$, cortisol, glucagon and glucose concentrations. Following blood collection at $4 \mathrm{~h}$, the piglets were humanely euthanised with pentobarbitone. The gastrocnemius and longissimus dorsi (LD) muscles were collected rapidly, frozen immediately in liquid $\mathrm{N}_{2}$ and then stored at $-80^{\circ} \mathrm{C}$ for further measurement. In many experiments, gastrocnemius and LD muscles were used for studying muscle atrophy $^{(25,26)}$. MAFbx was highly up-regulated in the gastrocnemius and LD muscles in piglets with porcine congenital splayleg, which is characterised by muscle fibre atrophy ${ }^{(26)}$. Thus, we were determined to choose these two muscles to study sepsis-induced atrophy. In addition, previous studies have found that, within 3-6h post injection, LPS increased the mRNA or protein expression of pro-inflammatory cytokines and caused tissue damage ${ }^{(23,24,27-29)}$. Besides, during the time frame, the mRNA and protein level of TLR4 was also upregulated $^{(24,30)}$. Therefore, the time point of $4 \mathrm{~h}$ after LPS or saline injection was selected for experimental measurements. 


\section{Plasma TNF- $\alpha$, cortisol, glucagon and glucose concentrations}

Plasma TNF- $\alpha$ concentration was analysed by using a commercially available porcine ELISA assay kit (R\&D Systems). Plasma cortisol and glucagon concentrations were measured with ${ }^{125}$ I RIA assay kits (Beijing North Institute of Biological Technology). Plasma glucose concentration was determined by the glucose GOD-PAP assay kit (DiaSys Diagnostic Systems $\mathrm{GmbH}$ ). All experimental procedures and data analyses were performed according to the manufacturer's instructions.

\section{Muscle protein, DNA and RNA contents}

Muscle protein, DNA and RNA contents were analysed using the method of Liu et al. ${ }^{(23)}$.

\section{mRNA abundance analysis by real-time PCR}

Total RNA extraction, quantification, complementary DNA synthesis and real-time PCR were in accordance with the method of Liu $e t a l .{ }^{(24)}$. The primer pairs used are presented in the online Supplementary Table S2. The expression of target genes $v$. housekeeping gene (glyceraldehyde 3-phosphate dehydrogenase; GAPDH) was computed using the formula $2^{-\Delta \Delta C_{T}}$ of Livak and Schmittgen ${ }^{(31)}$. The results of the present study suggested that there was no difference in the expression of GAPDH among four treatments. Relative mRNA abundance of every target gene was normalised to the control group.

\section{Protein abundance analysis by Western blot}

Protein immunoblot analysis was measured according to the previously described method ${ }^{(24)}$. In brief, the muscle samples were homogenised and centrifuged, and the supernatants were collected. The protein contents of the supernatants were measured using the bicinchoninic acid (BCA) reagent ${ }^{(24)}$. An equal amount of muscle proteins was loaded onto $10 \%$ polyacrylamide gels, separated through SDS-PAGE, transferred to blotting membranes and then incubated with the primary antibodies $^{(24)}$. After that, the membranes were incubated with the secondary antibody ${ }^{(24)}$. Specific primary antibodies included total AMPK $\alpha$ (tAMPK $\alpha$; 1:1000; no. 2532), phosphorylated AMPK $\alpha$ (pAMPK $\alpha$, Thr172; 1:1000; no. 2535), total Akt (tAkt, 1:1000; no. 9272), phosphorylated Akt (pAkt, serine 473; 1:1000; no. 9271), total FOXO 1 (tFOXO1; 1:1000; no. 9454) and phosphorylated FOXO 1 (pFOXO1, serine256; 1:1000; no. 9461) from Cell Signaling; MAFbx (1:1000; no. ab74023) from Abcam; MuRF1 (1:1000; no. 55456-1-AP) from Proteintech Group; and GAPDH (1:1000; no. ANT011) from Antgene Biotech. Blots were developed using an Enhanced Chemiluminescence Western blotting kit (Amersham), and visualised using a Gene Genome bioimaging system. Bands were analysed by densitometry using GeneTools software (Syngene). The relative abundance of target proteins (MAFbx and MuRF1) was expressed as the target protein:GAPDH protein ratio. The phosphorylated forms of AMPK $\alpha$, Akt and FOXO1 were normalised with the total protein content.

\section{Statistical analysis}

All experimental data were analysed by variance specific for repeated measurements using mixed procedure of SAS (SAS Institute Inc.), with treatments (CONTR, LPS, LPS + 0.5\% Asn, LPS $+1.0 \%$ Asn) as the between-animal effect and muscle (gastrocnemius muscle and LD muscle) as the within-animal effect. Only when a significant treatment $\times$ muscle interaction occurred, comparisons among treatments in each muscle was performed. The LPS piglets ( $0 \%$ Asn) were compared with CONTR piglets to determine the effect of LPS challenge. Linear and quadratic polynomial contrasts were used to determine the response to dietary Asn supplementation among LPSchallenged piglets. Results were expressed as means values with their pooled standard errors. Differences were considered as significant when $P \leq 0 \cdot 05$. Instances in which $0.05<P<0.10$ were taken to indicate trends.

\section{Results}

Plasma glucose, cortisol, glucagon and TNF- $\alpha$ concentrations

Relative to CONTR piglets, LPS challenge increased the concentrations of TNF- $\alpha$, cortisol and glucagon, and decreased glucose concentration in plasma $(P<0.01$; Table 1$)$. Among the LPS-challenged piglets, Asn supplementation decreased the concentrations of TNF- $\alpha$, cortisol and glucagon in plasma (linear, $P<0.01$; quadratic, $P<0.05$ ).

\section{Muscle protein, DNA and RNA contents}

The protein, DNA and RNA contents in LD muscle were higher than those in gastrocnemius muscle $(P<0.05$; Table 2$)$. No significant treatment $\times$ segment interaction was observed for protein and DNA contents. Overall, compared with CONTR piglets, LPS challenge decreased DNA content $(P<0 \cdot 001)$. Among the LPS-challenged piglets, Asn supplementation increased protein content (linear, $P=0.084$; quadratic, $P<0.05$ ).

There was significant treatment $\times$ segment interaction observed for RNA content $(P<0 \cdot 001)$. Among the LPSchallenged piglets, Asn supplementation increased RNA content in LD muscle (quadratic, $P<0.001$ ).

\section{Muscle mRNA and protein abundance of muscle atrophy F-box and muscle RING finger 1}

The mRNA abundance of MAFbx in gastrocnemius muscle was higher than that in LD muscle $(P<0 \cdot 05$; Table 3$)$, and the mRNA abundance of MURF1 in gastrocnemius muscle tended to be higher than that in LD muscle $(P=0 \cdot 071)$. There was treatment $\times$ segment interactions observed for the mRNA abundance of $M A F b x(P=0 \cdot 05)$. Relative to CONTR piglets, LPS challenge increased mRNA abundance of $M A F b x$ in gastrocnemius muscle $(P<0 \cdot 01)$. Among the LPS-challenged piglets, Asn supplementation decreased mRNA abundance of $M A F b x$ in gastrocnemius muscle (linear, $P<0.05$; quadratic, $P<0.05$ ). No significant treatment $\times$ segment interaction was found for the 
Table 1. Effects of asparagine (Asn) supplementation on plasma TNF-a, cortisol, glucagon and glucose concentrations in weaning piglets at $4 \mathrm{~h}$ after the administration of Escherichia coli lipopolysaccharide (LPS) challenge

(Mean values with their pooled standard errors; $n 6$ (one piglet per pen))

\begin{tabular}{|c|c|c|c|c|c|c|c|c|}
\hline \multirow[b]{2}{*}{ Items } & \multicolumn{4}{|c|}{ Treatment } & \multirow[b]{2}{*}{ SEM } & \multicolumn{3}{|c|}{$P^{\star}$} \\
\hline & CONTR & LPS & LPS $+0.5 \%$ Asn & LPS $+1.0 \%$ Asn & & LPS $v$. CONTR & Linear & Quadratic \\
\hline TNFa (pg/ml) & ND & 5846 & 5256 & 1548 & 858 & $<0.001$ & 0.008 & 0.016 \\
\hline Cortisol (ng/ml) & 55 & 242 & 201 & 166 & 13 & $<0.001$ & 0.001 & 0.004 \\
\hline Glucagon (pg/ml) & 126 & 316 & 256 & 223 & 19 & $<0.001$ & 0.007 & 0.025 \\
\hline Glucose $(\mathrm{mmol} / \mathrm{l})$ & 7.97 & $5 \cdot 80$ & 6.14 & 5.90 & 0.34 & 0.004 & 0.810 & 0.702 \\
\hline
\end{tabular}

CONTR, non-challenged control; ND, not detectable.

* The LPS pigs were compared with CONTR pigs to determine the effect of LPS. Linear and quadratic polynomial contrasts were used to determine the response to Asn supplementation among LPS-challenged pigs.

Table 2. Effects of asparagine (Asn) supplementation on muscle protein, DNA and RNA contents in weaning piglets at $4 \mathrm{~h}$ after the administration of Escherichia coli lipopolysaccharide (LPS) challenge

(Mean values with their pooled standard errors; $n 6$ (one piglet per pen))

\begin{tabular}{|c|c|c|c|c|c|c|c|c|c|c|c|c|}
\hline \multirow[b]{2}{*}{ Items } & \multirow[b]{2}{*}{ Muscle (M) } & \multicolumn{4}{|c|}{ Treatment $(\mathrm{T})$} & \multirow[b]{2}{*}{ SEM } & \multicolumn{3}{|c|}{$P^{\star}$} & \multicolumn{3}{|c|}{$P+$} \\
\hline & & CONTR & LPS & $\begin{array}{c}\text { LPS + } \\
0.5 \% \text { Asn }\end{array}$ & $\begin{array}{c}\text { LPS + } \\
1.0 \% \text { Asn }\end{array}$ & & $\mathrm{T}$ & M & $\mathrm{T} \times \mathrm{M}$ & $\begin{array}{l}\text { LPS } v \text {. } \\
\text { CONTR }\end{array}$ & Linear & Quadratic \\
\hline \multirow[t]{2}{*}{ Protein (mg/g tissue) } & GM & 49 & 52 & 59 & 54 & 3 & 0.030 & $<0.001$ & 0.186 & 0.879 & 0.084 & 0.036 \\
\hline & LDM & 84 & 81 & 95 & 94 & 3 & & & & & & \\
\hline \multirow[t]{2}{*}{ DNA ( $\mu \mathrm{g} / \mathrm{g}$ tissue) } & GM & 85 & 59 & 67 & 66 & 7 & $<0.001$ & 0.022 & 0.125 & $<0.001$ & 0.839 & 0.979 \\
\hline & LDM & 122 & 74 & 67 & 70 & 8 & & & & & & \\
\hline \multirow[t]{2}{*}{ RNA ( $\mu \mathrm{g} / \mathrm{g}$ tissue) } & GM & 141 & 152 & 172 & 169 & 10 & $<0.001$ & $<0.001$ & $<0.001$ & 0.166 & 0.330 & 0.452 \\
\hline & LDM & 200 & 216 & 324 & 256 & 13 & & & & 0.380 & 0.198 & $<0.001$ \\
\hline
\end{tabular}

CONTR, non-challenged control; GM, gastrocnemius muscle; LDM, longissimus dorsi muscle.

* $P$ values were obtained using treatment as the main effect and by analysing data from the GM and LDM as repeated measures.

$\dagger$ The LPS pigs were compared with CONTR pigs to determine the effect of LPS. Linear and quadratic polynomial contrasts were used to determine the response to Asn supplementation among LPS-challenged pigs.

Table 3. Effects of asparagine (Asn) supplementation on muscle mRNA expression of AMP-activated protein kinase $a$ (AMPKa), protein kinase B (Akt) signals and their target genes in weaning piglets at $4 \mathrm{~h}$ after the administration of Escherichia coli lipopolysaccharide (LPS) challenge (Mean values with their pooled standard errors; $n 6$ (one piglet per pen))

\begin{tabular}{|c|c|c|c|c|c|c|c|c|c|c|c|c|}
\hline \multirow[b]{2}{*}{ Items } & \multirow[b]{2}{*}{ Muscle (M) } & \multicolumn{4}{|c|}{ Treatment $(\mathrm{T})$} & \multirow[b]{2}{*}{ SEM } & \multicolumn{3}{|c|}{$P^{\star}$} & \multicolumn{3}{|c|}{$P \dagger$} \\
\hline & & CONTR & LPS & $\begin{array}{c}\text { LPS + } \\
0.5 \% \text { Asn }\end{array}$ & $\begin{array}{c}\text { LPS + } \\
1.0 \% \text { Asn }\end{array}$ & & $\mathrm{T}$ & M & $\mathrm{T} \times \mathrm{M}$ & $\begin{array}{l}\text { LPS } v \text {. } \\
\text { CONTR }\end{array}$ & Linear & Quadratic \\
\hline \multirow[t]{2}{*}{ AMPKa 1} & GM & 1.00 & 0.96 & $1 \cdot 32$ & $1 \cdot 18$ & 0.18 & 0.746 & 0.029 & 0.075 & 0.904 & 0.255 & 0.152 \\
\hline & LDM & 1.00 & 1.02 & 0.98 & 0.76 & 0.10 & & & & 0.903 & 0.038 & 0.084 \\
\hline \multirow[t]{2}{*}{ AMPKa2 } & GM & 1.00 & 0.98 & 1.54 & 1.47 & 0.18 & 0.118 & 0.005 & 0.057 & 0.916 & 0.076 & 0.079 \\
\hline & LDM & 1.00 & 0.93 & $1 \cdot 15$ & 0.86 & 0.11 & & & & 0.601 & 0.694 & 0.193 \\
\hline \multirow[t]{2}{*}{ Akt1 } & GM & 1.00 & 0.86 & $0 \cdot 81$ & 0.77 & 0.08 & 0.080 & 0.812 & 0.856 & 0.250 & 0.171 & 0.364 \\
\hline & LDM & 1.00 & 0.87 & 0.87 & 0.73 & 0.07 & & & & & & \\
\hline \multirow[t]{2}{*}{ FOXO1 } & GM & 1.00 & $2 \cdot 12$ & $2 \cdot 01$ & $2 \cdot 06$ & 0.20 & $<0.001$ & $<0.001$ & 0.020 & 0.005 & 0.694 & 0.940 \\
\hline & LDM & 1.00 & 2.80 & 3.00 & 2.96 & 0.26 & & & & $<0.001$ & 0.710 & 0.889 \\
\hline \multirow[t]{2}{*}{ FOXO4 } & GM & 1.00 & 1.06 & 0.82 & 0.96 & 0.08 & 0.002 & $<0.001$ & 0.030 & 0.575 & 0.467 & 0.207 \\
\hline & LDM & 1.00 & 0.92 & $0 \cdot 61$ & 0.58 & 0.05 & & & & 0.183 & 0.001 & 0.001 \\
\hline \multirow[t]{2}{*}{ MAFbx } & GM & 1.00 & 2.08 & 1.23 & $1 \cdot 22$ & 0.24 & 0.107 & 0.047 & 0.050 & 0.007 & 0.033 & 0.046 \\
\hline & LDM & 1.00 & 1.08 & 1.28 & 1.00 & 0.19 & & & & 0.759 & 0.744 & 0.513 \\
\hline \multirow[t]{2}{*}{ MuRF1 } & GM & 1.00 & 4.85 & 3.89 & 2.98 & 0.45 & $<0.001$ & 0.071 & 0.407 & $<0.001$ & 0.001 & 0.005 \\
\hline & LDM & 1.00 & 4.59 & 3.66 & $2 \cdot 15$ & 0.31 & & & & & & \\
\hline
\end{tabular}

CONTR, non-challenged control; GM, gastrocnemius muscle; LDM, Iongissimus dorsi muscle; FOXO, Forkhead Box O; MAFbx, muscle atrophy F-box; MuRF1, muscle RING finger 1.

${ }^{*} P$ values were obtained using treatment as the main effect and by analysing data from the GM and LDM as repeated measures.

† The LPS pigs were compared with CONTR pigs to determine the effect of LPS. Linear and quadratic polynomial contrasts were used to determine the response to Asn supplementation among LPS-challenged pigs.

mRNA abundance of MuRF1. Overall, compared with CONTR pigs, LPS challenge resulted in an increase in the mRNA abundance of MuRF1 $(P<0.001)$. Among the LPS-challenged pigs, Asn supplementation decreased the mRNA abundance of MuRF1 (linear, $P=0.001$; quadratic, $P<0 \cdot 01$ ).
The protein abundance of MuRF1 in gastrocnemius muscle was higher than that in LD muscle $(P<0 \cdot 05 ;$ Fig. 1). No significant treatment $\times$ segment interaction was found for the protein abundance of MAFbx and MuRF1. Neither LPS nor Asn treatment affected the protein abundance of MAFbx and MuRF1. 

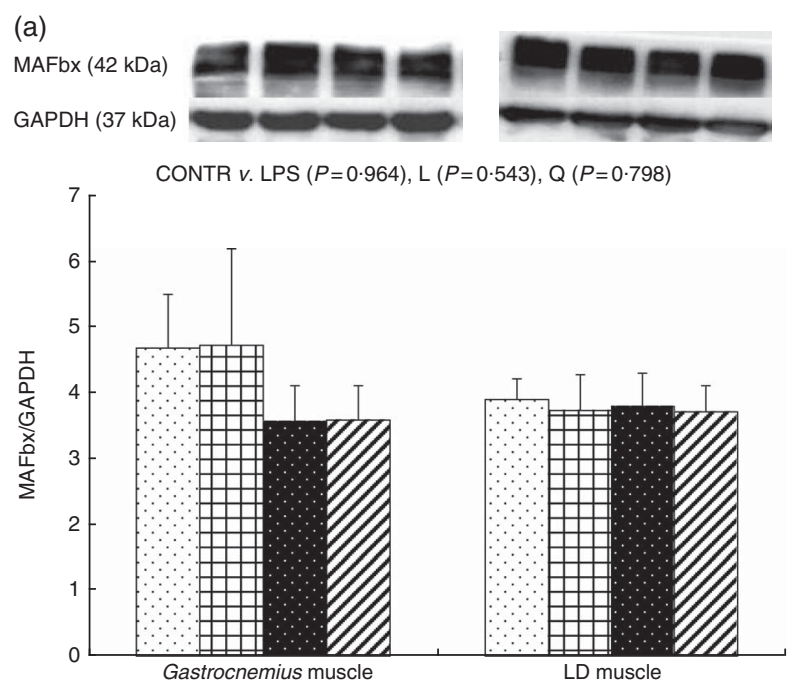

(b)
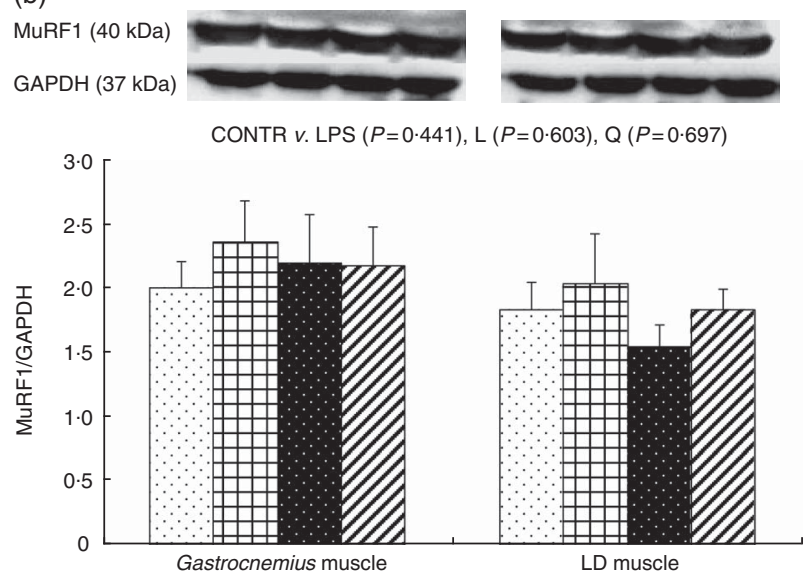

Fig. 1. Effects of asparagine (Asn) supplementation on protein abundance of (a) muscle atrophy F-box (MAFbx) and (b) muscle RING finger 1 (MuRF1) in muscles of weaning piglets at $4 \mathrm{~h}$ after the administration of Escherichia coli lipopolysaccharide (LPS) challenge. The bands shown are the representative Western blot images of MAFbx (42 kDa), MuRF1 ( $40 \mathrm{kDa}$ ) and glyceraldehyde 3phosphate dehydrogenase (GAPDH) $(37 \mathrm{kDa})$. The data were analysed as repeated measures with treatments $(\square$, non-challenged control (CONTR); 田, LPS; - LPS + $0.5 \%$ Asn; 7 , LPS $+1.0 \%$ Asn) as the between-animal effect and muscle (gastrocnemius muscle and longissimus dorsi (LD) muscle) as the withinanimal effect. The LPS (0\% Asn) pigs were compared with CONTR pigs (LPS $v$. CONTR) to determine the effect of LPS. Linear (L) and quadratic (Q) polynomial contrasts were used to determine the response to Asn supplementation among LPS-challenged pigs. Values are means ( $n=6$; one pig per pen), with standard errors. The protein abundance of MuRF1 in gastrocnemius muscle was higher than that in LD muscle $(P=0.011)$. No significant treatment $\times$ segment interaction was found for the protein abundance of MAFbx $(P=0.473)$ and MuRF1 $(P=0.630)$.

\section{Muscle mRNA abundance of AMP-activated protein kinase $\alpha$, protein kinase $B /$ Forkhead Box $O$ signalling}

The mRNA abundance of AMPK $1, A M P K \alpha 2$ and FOXO4 in gastrocnemius muscle was higher than that in LD muscle $(P<0.05$; Table 3$)$. The mRNA abundance of FOXO1 in gastrocnemius muscle was lower than that in LD muscle $(P<0 \cdot 001)$. There were treatment $\times$ segment interactions observed for the mRNA abundance of FOXO1 and FOXO4 $(P<0 \cdot 05)$, and trends for treatment $\times$ segment interaction observed for the mRNA abundance of $A M P K \alpha 1 \quad(P=0.075)$ and $A M P K \alpha 2(P=0.057)$. Relative to CONTR piglets, LPS challenge increased mRNA abundance of FOXO1 in gastrocnemius and LD muscles $(P<0 \cdot 01)$. Among the LPS-challenged piglets, Asn supplementation decreased mRNA abundance of $A M P K \alpha 1$ (linear, $P<0 \cdot 05$; quadratic, $P=0.084$ ) and FOXO4 (linear, $P=0.001$; quadratic, $P=0.001)$ in LD muscle, and tended to increase mRNA abundance of $A M P K \alpha 2$ in gastrocnemius muscle (linear, $P=0.076$; quadratic, $P=0.079)$. No significant treatment $\times$ segment interaction was found for the mRNA abundance of Akt1. Neither LPS nor Asn treatment affected the mRNA abundance of Akt1.

\section{Muscle protein phosphorylation and abundance of AMP- activated protein kinase $\alpha$, protein kinase $B$ and Forkhead Box 01}

The ratios of pAMPK $\alpha$ :tAMPK $\alpha$ and pAkt:tAkt and the protein abundance of tAkt and tFOXO1 in gastrocnemius muscle were higher than those in LD muscle, and the protein abundance of tAMPK $\alpha$ and the ratio of pFOXO1:tFOXO1 in gastrocnemius muscle were lower than those in LD muscle ( $P \leq 0 \cdot 001$; Fig. 2-4). A trend for treatment $\times$ segment interaction was observed for pAMPK $\alpha$ :tAMPK $\alpha$ ratio $(P=0 \cdot 069)$. Relative to CONTR piglets, LPS challenge increased the ratio of $\mathrm{pAMPK} \alpha$ :tAMPK $\alpha$ in gastrocnemius muscle $(P<0 \cdot 01)$. Among the LPS-challenged piglets, Asn supplementation decreased the ratio of $\operatorname{pAMPK} \alpha$ :AMPK $\alpha$ in gastrocnemius and LD muscles (linear and quadratic, $P<0 \cdot 01$ ).

No significant treatment $\times$ segment interaction was found for the protein abundance of tAMPK $\alpha$, tAkt and tFOXO1, and the ratios of pAkt:tAkt and pFOXO1:tFOXO1. Overall, relative to CONTR piglets, LPS challenge decreased the ratio of pAkt:tAkt $(P<0 \cdot 001)$. Among the LPS-challenged piglets, Asn supplementation increased the protein abundance of tAMPK $\alpha$ (linear, $P<0.05$; quadratic, $P=0.075)$, and the ratios of pAkt:tAkt (linear, $P<0.05$; quadratic, $P<0.05$ ) and pFOXO1:tFOXO1 (linear, $P<0.05$ ), and tended to increase the protein abundance of tAkt (linear, $P=0.097$ ).

\section{Muscle mRNA abundance of toll-like receptor 4 and nucleotide-binding oligomerisation domain proteins and their downstream signals}

The mRNA abundance of TNF receptor-associated factor 6 (TRAFO) in gastrocnemius muscle was higher than that in LD muscle, and the mRNA abundance of TNF- $\alpha$ in gastrocnemius muscle was lower than that in LD muscle $(P<0.05$; Table 4$)$. No significant treatment $\times$ segment interaction was observed for the mRNA abundance of TLR4, myeloid differentiation factor 88 (MyD88), IL-1 receptor-associated kinase 1, TRAF6, NOD1, $N O D 2$, receptor-interacting serine/threonine-protein kinase 2 (RIPK2) and $N F-\kappa B p 65$. Compared with CONTR piglets, LPS challenge increased mRNA abundance of TLR4, MyD88, NOD2 and RIPK2 $(P<0 \cdot 05)$, and tended to increase mRNA abundance of $N F-\kappa B p 65$ ( $P=0.052)$. Among the LPS-challenged piglets, Asn supplementation decreased mRNA abundance of TLR4 (linear, $P=0.01$; quadratic, $P<0.01$ ), $M y D 88$ (linear, $P<0.05$; quadratic, $P<0.05$ ), NOD1 (linear, $P<0.05$; quadratic, $P<0.05$ ) and NOD2 
(a)

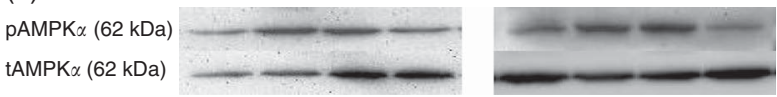

Gastrocnemius muscle: CONTR $v$. LPS $(P=0.006), \mathrm{L}(P=0.006), \mathrm{Q}(P=0.002)$ LD muscle: CONTR $v$. LPS $(P=0.831), \mathrm{L}(P=0.007), \mathrm{Q}(P=0.007)$

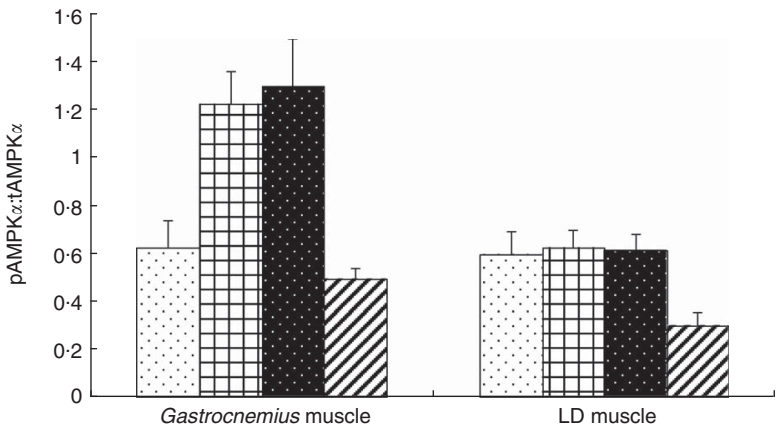

(b) CONTR v. LPS $(P=0 \cdot 475), \mathrm{L}(P=0.021), \mathrm{Q}(P=0.075)$

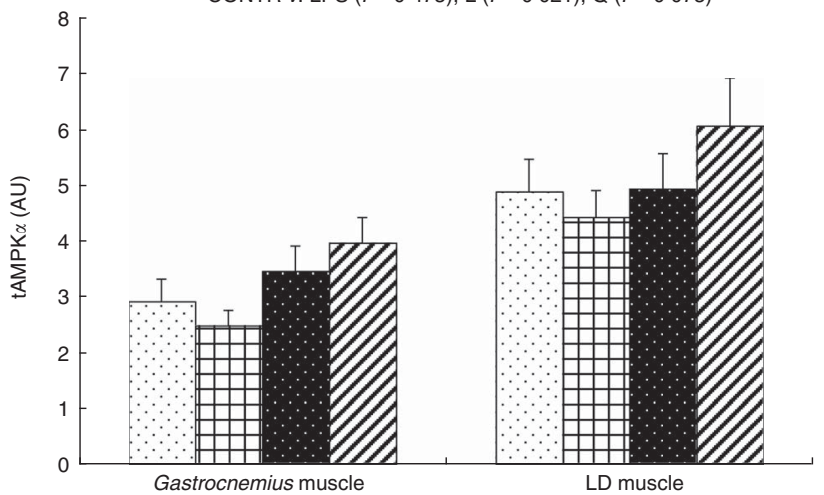

Fig. 2. Effects of asparagine (Asn) supplementation on the (a) phosphorylated AMP-activated protein kinase (pAMPKa):total AMP-activated protein kinase (tAMPKa) ratio and (b) protein abundance of tAMPKa in muscles of weaning piglets at $4 \mathrm{~h}$ after the administration of Escherichia coli lipopolysaccharide (LPS) challenge. The bands shown are the representative Western blot images of pAMPKa $(62 \mathrm{kDa})$ and tAMPKa $(62 \mathrm{kDa})$. The data were analysed as repeated measures with treatments $(\square$, non-challenged control (CONTR); 田 LPS; . ., LPS + 0.5\% Asn; [, LPS $+1.0 \%$ Asn) as the between-animal effect and muscle (gastrocnemius muscle and longissimus dorsi (LD) muscle) as the within-animal effect. The LPS ( $0 \%$ Asn) pigs were compared with CONTR pigs (LPS $v$. CONTR) to determine the effect of LPS. Linear (L) and quadratic (Q) polynomial contrasts were used to determine the response to Asn supplementation among LPS-challenged pigs. Values are means $(n 6$; one pig per pen) with standard errors. The ratio of pAMPKa:tAMPKa in gastrocnemius muscle was higher than that in LD muscle $(P=0.001)$, and the protein abundance of tAMPKa in gastrocnemius muscle tended to be lower than that in LD muscle $(P<0.001)$. A trend for treatment $\times$ segment interaction was observed for pAMPKa:tAMPKa ratio $(P=0.069)$. No significant treatment $\times$ segment interaction was found for the protein abundance of tAMPKa $(P=0.894)$. AU, arbitrary units.

(linear, $P<0.05)$, and tended to decrease mRNA abundance of TRAF6 (linear, $P=0.070$ ) and $N F-\kappa B p 65$ (linear, $P=0.082$ ).

There was a trend for treatment $\times$ segment interaction observed for the mRNA abundance of TNF- $\alpha(P=0.094)$. Compared with CONTR piglets, LPS challenge increased mRNA abundance of $T N F-\alpha$ in gastrocnemius and LD muscles $(P<0 \cdot 01)$. Among the LPS-challenged piglets, Asn supplementation decreased mRNA abundance of TNF- $\alpha$ in gastrocnemius and LD muscles (linear and quadratic, $P<0.05$ ). (a)
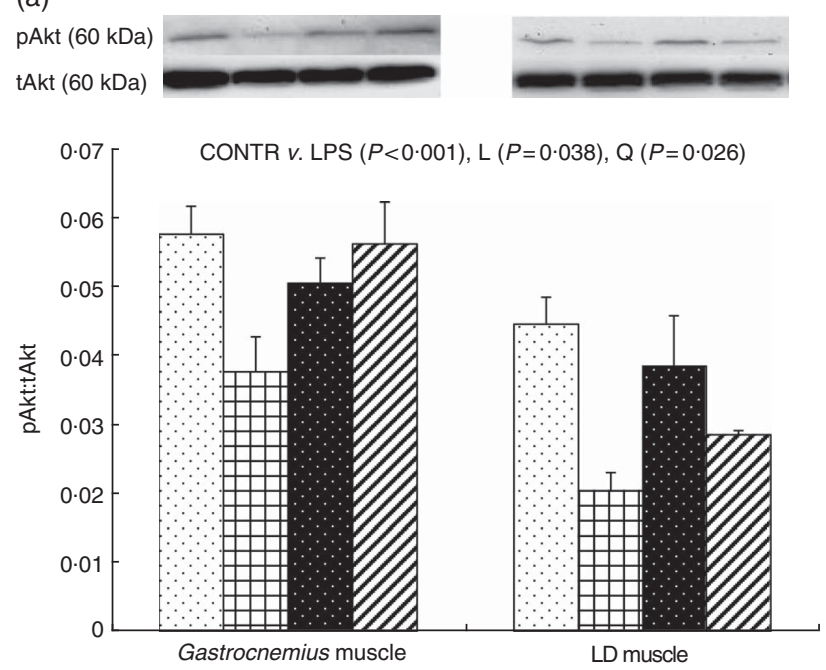

(b) CONTR $v$. LPS $(P=0 \cdot 748), \mathrm{L}(P=0.097), \mathrm{Q}(P=0 \cdot 189)$

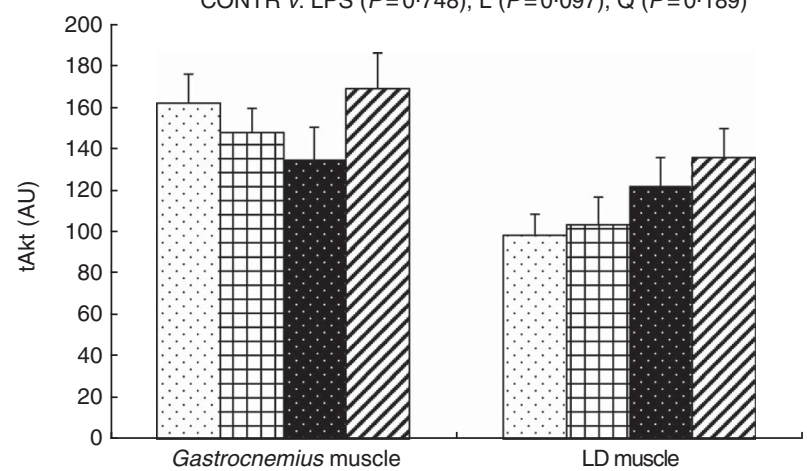

Fig. 3. Effects of asparagine (Asn) supplementation on the (a) phosphorylated protein kinase $B$ (Akt) (pAkt):total Akt (tAkt) ratio and (b) protein abundance of tAkt in muscles of weaning piglets at $4 \mathrm{~h}$ after the administration of Escherichia coli lipopolysaccharide (LPS) challenge. The bands shown are the representative Western blot images of pAkt $(60 \mathrm{kDa})$ and tAkt $(60 \mathrm{kDa})$. The data were analysed as repeated measures with treatments $([$,$] , non-challenged$ control (CONTR); $⿴$, LPS; . , LPS + $0.5 \%$ Asn; Q LPS $+1.0 \%$ Asn) as the between-animal effect and muscle (gastrocnemius muscle and longissimus dorsi (LD) muscle) as the within-animal effect. The LPS (0\% Asn) pigs were compared with CONTR pigs (LPS $v$. CONTR) to determine the effect of LPS. Linear $(L)$ and quadratic $(Q)$ polynomial contrasts were used to determine the response to Asn supplementation among LPS-challenged pigs. Values are means ( $n$ 6; one pig per pen), with standard errors. The ratio of pAkt:tAkt $(P<0.001)$ and the protein abundance of tAkt $(P=0.001)$ in gastrocnemius muscle were higher than those in LD muscle. No significant treatment $\times$ segment interaction was found for the ratio of pAkt:tAkt $(P=0.211)$ and the protein abundance of tAkt $(P=0.335)$. AU, arbitrary units.

Muscle mRNA abundance of negative regulators of toll-like receptor 4 and nucleotide-binding oligomerisation domain proteins signalling pathways

The mRNA abundance of radioprotective 105 (RP105) in gastrocnemius muscle was lower than that in LD muscle $(P<0 \cdot 001$; Table 5), and the mRNA abundance of toll-interacting protein (Tollip) in gastrocnemius muscle tended to be higher than that in LD muscle $(P=0.094)$. Significant treatment $\times$ segment interactions were observed for the mRNA abundance of $R P 105$ and suppressor of cytokine signalling 1 (SOCS1) $(P<0 \cdot 01)$. 
(a)
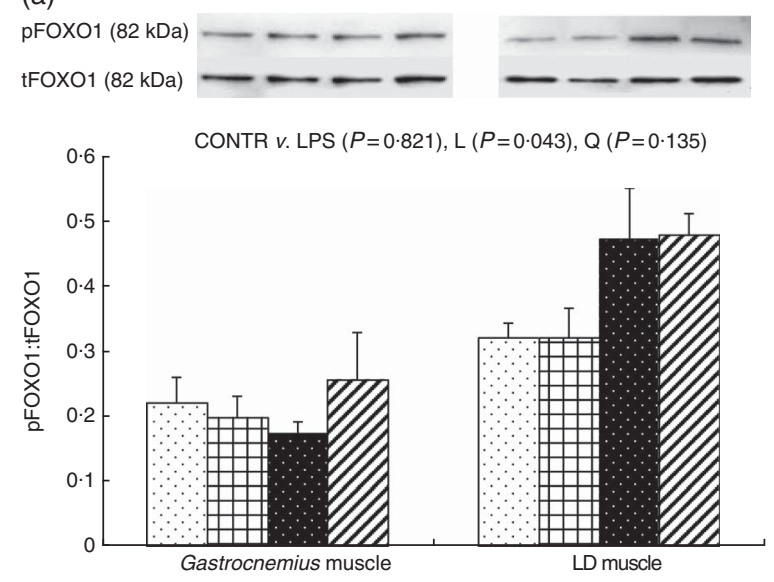

(b)

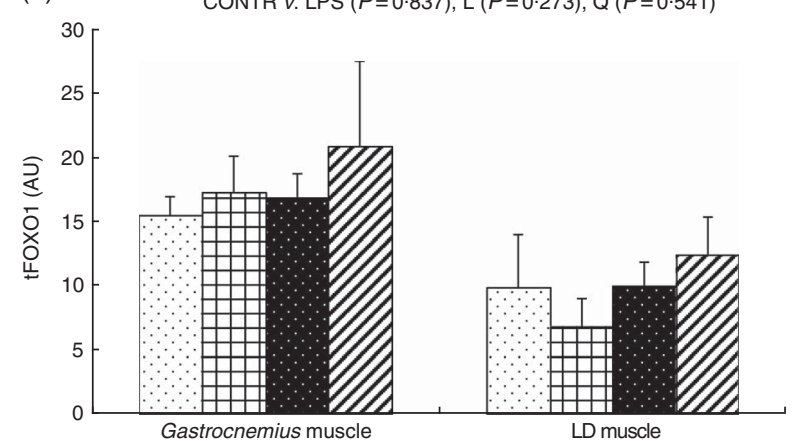

Fig. 4. Effects of asparagine (Asn) supplementation on the (a) phosphorylated Forkhead Box O (pFOXO):total Forkhead Box O (tFOXO) ratio and (b) protein abundance of $\mathrm{tFOXO}$ in muscles of weaning piglets at $4 \mathrm{~h}$ after the administration of Escherichia coli lipopolysaccharide (LPS) challenge. The bands shown are the representative Western blot images of pFOXO $(82 \mathrm{kDa})$ and tFOXO $(82 \mathrm{kDa})$. The data were analysed as repeated measures with treatments $(\square$, nonchallenged control (CONTR); 田, LPS; . ., LPS + $0.5 \%$ Asn; [, LPS + $1.0 \%$ Asn) as the between-animal effect and muscle (gastrocnemius muscle and longissimus dorsi (LD) muscle) as the within-animal effect. The LPS ( $0 \%$ Asn) pigs were compared with CONTR pigs (LPS v. CONTR) to determine the effect of LPS. Linear (L) and quadratic (Q) polynomial contrasts were used to determine the response to Asn supplementation among LPS-challenged pigs. Values are means ( $n 6$; one pig per pen), with standard errors. The ratio of pFOXO1:tFOXO1 in gastrocnemius muscle was lower than that in LD muscle $(P<0.001)$, and the protein abundance of $\mathrm{tFOXO1}$ in gastrocnemius muscle was higher than that in LD muscle $(P=0.001)$. No significant treatment $\times$ segment interaction was found for the ratio of pFOXO1:tFOXO1 $(P=0.159)$ and the protein abundance of tFOXO1 $(P=0.833)$. AU, arbitrary units.

Compared with CONTR piglets, LPS challenge increased mRNA abundance of RP105 in gastrocnemius muscle, and SOCS1 in gastrocnemius and LD muscles $(P<0.05)$. Among the LPS-challenged piglets, Asn supplementation decreased mRNA abundance of RP105 (linear and quadratic, $P<0.05$ ) and SOCS1 (linear, $P<0 \cdot 05$; quadratic, $P=0 \cdot 081$ ) in LD muscle.

No significant treatment $\times$ segment interaction was observed for the mRNA abundance of Tollip, single Ig IL-1 R-related molecule (SIGIRR), Erbb2-interacting protein (ERBB2IP) and centaurin $\beta 1$ (CENTB1). Overall, compared with CONTR pigs, LPS challenge decreased mRNA abundance of Tollip $(P=0.05)$, and tended to increase mRNA abundance of CENTB1 $(P=0.074)$. Among the LPS-challenged piglets, Asn supplementation decreased mRNA abundance of CENTB1 (linear and quadratic, $P<0 \cdot 01$ ), and tended to increased mRNA abundance of Tollip (quadratic, $P=0.064$ ).

\section{Discussion}

Protein or amino acid supplementation exerts a regulatory effect on both protein synthesis and protein degradation ${ }^{(32,33)}$. As stated in a recent review, protein or amino acids are more effective than carbohydrate in increasing lean or fat-free body mass and whole-muscle cross-sectional area ${ }^{(33)}$. Amino acid supplementation also stimulates the synthesis of both myofibrillar and sarcoplasmic proteins ${ }^{(32)}$. However, the molecular mechanisms by which protein or amino acids affect muscle protein metabolism are presently unknown. Our present study offered a new basis to explain the beneficial effects of amino acid in the skeletal muscle. We found that Asn supplementation had beneficial effects on muscle atrophy, as indicated by the increase of muscle protein and RNA contents, and the down-regulation of ubiquitin ligases MAFbx and MuRF1 mRNA transcription. These changes were accompanied by increased phosphorylation (activation) of Akt1 protein, and reduced phosphorylation (inhibition) of AMPK and FOXO1 in muscles. Also, these changes were concurrent with decreased circulating level of TNF- $\alpha$ and decreased mRNA transcription of muscle TLR4 and NOD and their downstream signals. Overall, the present data suggest that Asn exerts a positive effect on LPSinduced muscle atrophy, which is associated with regulating Akt, AMPK $\alpha$, TLR4 and NOD signalling.

Muscle atrophy occurs when protein degradation exceeds protein synthesis, leading to a net loss of muscle protein ${ }^{(1,34)}$. The muscle protein, RNA and DNA are common metrics for assessing the protein synthetic capacity, translational efficiency and cell size, and they are negatively related to protein degradation $^{(35)}$. MAFbx and MuRF1, induced early in the atrophy process $^{(36)}$, are thought to be the accurate markers of the atrophy process ${ }^{(6)}$. The increased expression of the MAFbx and MuRF1 precedes the loss of muscle weight ${ }^{(36)}$, and have been described in several models of muscle atrophy ${ }^{(37)}$. In this study, LPS administration resulted in decreased DNA content and increased mRNA expression of MAFbx and MuRF1 in muscles, indicating LPS-induced muscle atrophy. Our results are in agreement with previous observations of up-regulation of MAFbx and MuRF1 in endotoxaemia ${ }^{(38)}$, and their central role in the initiation and regulation of muscle protein degradation via the ubiquitin-proteasome pathway during atrophy ${ }^{(39)}$. Asn supplementation to the LPS-challenged piglets increased protein and RNA content in muscles, and decreased muscle mRNA expression of $M A F b x$ and MuRF1, indicating that Asn is effective in attenuating LPS-induced muscle atrophy. However, in this study, neither LPS nor Asn treatment affected the protein abundance of MuRF1 and MAFbx. Many reports on mRNA and protein abundances find that mRNA and protein are differentially expressed, and the discrepancy may be attributed to different levels of regulation between transcript and protein product ${ }^{(40,41)}$. Previous studies have shown that, within $8-24 \mathrm{~h}$ post injection, LPS increased the protein abundance of MuRF1 and $\operatorname{MAFbx}^{(2,15)}$. We speculated that gene up-regulation may occur at an earlier stage than protein production. 
Table 4. Effects of asparagine (Asn) supplementation on muscle mRNA expression of toll-like receptor 4 (TLR4) and nucleotide-binding oligomerisation domain proteins (NOD) and their downstream signals in weaning piglets at $4 \mathrm{~h}$ after the administration of Escherichia coli lipopolysaccharide (LPS) challenge (Mean values with their pooled standard errors; $n 6$ (one piglet per pen))

\begin{tabular}{|c|c|c|c|c|c|c|c|c|c|c|c|c|}
\hline \multirow[b]{2}{*}{ Items } & \multirow[b]{2}{*}{ Muscle (M) } & \multicolumn{4}{|c|}{ Treatment $(\mathrm{T})$} & \multirow[b]{2}{*}{ SEM } & \multicolumn{3}{|c|}{$P^{*}$} & \multicolumn{3}{|c|}{$P \dagger$} \\
\hline & & CONTR & LPS & $\begin{array}{c}\text { LPS + } \\
0.5 \% \text { Asn }\end{array}$ & $\begin{array}{c}\text { LPS + } \\
1.0 \% \text { Asn }\end{array}$ & & $\mathrm{T}$ & $\mathrm{M}$ & $\mathrm{T} \times \mathrm{M}$ & $\begin{array}{l}\text { LPS } v \text {. } \\
\text { CONTR }\end{array}$ & Linear & Quadratic \\
\hline \multirow[t]{2}{*}{ TLR4 } & GM & 1.00 & 2.47 & 1.59 & 1.56 & 0.22 & 0.001 & 0.598 & 0.985 & 0.002 & 0.010 & 0.009 \\
\hline & LDM & 1.00 & $2 \cdot 40$ & 1.45 & 1.50 & 0.25 & & & & & & \\
\hline \multirow[t]{2}{*}{ MyD88 } & GM & 1.00 & 2.54 & 1.77 & 1.96 & 0.22 & $<0.001$ & 0.188 & 0.538 & $<0.001$ & 0.023 & 0.017 \\
\hline & LDM & 1.00 & $2 \cdot 81$ & 1.99 & 1.94 & 0.18 & & & & & & \\
\hline \multirow[t]{2}{*}{ IRAK1 } & GM & 1.00 & 1.00 & 0.99 & 1.01 & 0.10 & 0.800 & 0.464 & 0.721 & 0.852 & 0.364 & 0.641 \\
\hline & LDM & 1.00 & 1.04 & 0.92 & 0.87 & 0.06 & & & & & & \\
\hline \multirow[t]{2}{*}{ TRAF6 } & GM & 1.00 & $1 \cdot 30$ & $1 \cdot 22$ & $1 \cdot 21$ & 0.16 & 0.226 & 0.049 & 0.308 & 0.116 & 0.070 & 0.185 \\
\hline & LDM & 1.00 & 1.27 & 1.00 & 0.86 & 0.08 & & & & & & \\
\hline \multirow[t]{2}{*}{ NOD1 } & GM & 1.00 & 0.96 & 0.81 & 0.64 & 0.14 & 0.054 & 0.873 & 0.583 & 0.823 & 0.013 & 0.048 \\
\hline & LDM & 1.00 & 1.15 & 0.69 & 0.52 & 0.17 & & & & & & \\
\hline \multirow[t]{2}{*}{ NOD2 } & GM & 1.00 & 2.93 & 1.93 & 1.60 & 0.41 & 0.007 & 0.820 & 0.680 & 0.026 & 0.042 & 0.117 \\
\hline & LDM & 1.00 & 2.55 & 2.02 & 1.74 & 0.27 & & & & & & \\
\hline \multirow[t]{2}{*}{ RIPK2 } & GM & 1.00 & 2.59 & $2 \cdot 12$ & $2 \cdot 29$ & 0.25 & $<0.001$ & 0.275 & 0.720 & $<0.001$ & 0.650 & 0.433 \\
\hline & LDM & 1.00 & $2 \cdot 18$ & 1.97 & $2 \cdot 24$ & 0.17 & & & & & & \\
\hline \multirow[t]{2}{*}{$N F-\kappa B p 65$} & GM & 1.00 & 1.38 & 1.02 & 1.09 & 0.12 & 0.085 & 0.897 & 0.262 & 0.052 & 0.082 & 0.118 \\
\hline & LDM & 1.00 & 1.24 & $1 \cdot 17$ & $1 \cdot 11$ & 0.06 & & & & & & \\
\hline \multirow[t]{2}{*}{$T N F-a$} & GM & 1.00 & 2.09 & 1.45 & $1 \cdot 10$ & 0.19 & $<0.001$ & 0.001 & 0.094 & 0.008 & $<0.001$ & 0.001 \\
\hline & LDM & 1.00 & $3 \cdot 19$ & $2 \cdot 15$ & 1.64 & 0.32 & & & & 0.008 & 0.007 & 0.025 \\
\hline
\end{tabular}

CONTR, non-challenged control; GM, gastrocnemius muscle; LDM, longissimus dorsi muscle; MyD88, myeloid differentiation factor 88; IRAK1, IL-1 receptor-associated kinase 1; RIPK2, receptor-interacting serine/threonine-protein kinase 2; TRAF6, TNF receptor-associated factor 6.

* $P$ values were obtained using treatment as the main effect and by analysing data from the GM and LDM as repeated measures.

† The LPS pigs were compared with CONTR pigs to determine the effect of LPS. Linear and quadratic polynomial contrasts were used to determine the response to Asn supplementation among LPS-challenged pigs.

Table 5. Effects of asparagine (Asn) supplementation on muscle mRNA expression of negative regulators of toll-like receptor 4 (TLR4) and nucleotide-binding oligomerisation domain proteins (NOD) signalling pathways in weaning piglets at $4 \mathrm{~h}$ after the administration of Escherichia coli lipopolysaccharide (LPS) challenge (Mean values with their pooled standard errors; $n 6$ (one piglet per pen))

\begin{tabular}{|c|c|c|c|c|c|c|c|c|c|c|c|c|}
\hline \multirow[b]{2}{*}{ Items } & \multirow[b]{2}{*}{ Muscle (M) } & \multicolumn{4}{|c|}{ Treatment $(\mathrm{T})$} & \multirow[b]{2}{*}{ SEM } & \multicolumn{3}{|c|}{$P^{\star}$} & \multicolumn{3}{|c|}{$P+$} \\
\hline & & CONTR & LPS & $\begin{array}{c}\text { LPS + } \\
0.5 \% \text { Asn }\end{array}$ & $\begin{array}{c}\text { LPS + } \\
1.0 \% \text { Asn }\end{array}$ & & $\mathrm{T}$ & $M$ & $\mathrm{~T} \times \mathrm{M}$ & $\begin{array}{l}\text { LPS } v \text {. } \\
\text { CONTR }\end{array}$ & Linear & Quadratic \\
\hline \multirow[t]{2}{*}{$R P 105$} & GM & 1.00 & 1.14 & 0.82 & 0.92 & 0.31 & 0.033 & $<0.001$ & 0.002 & 0.788 & 0.648 & 0.793 \\
\hline & LDM & 1.00 & 3.86 & 1.52 & 1.35 & 0.53 & & & & 0.017 & 0.012 & 0.018 \\
\hline \multirow[t]{2}{*}{ SOCS1 } & GM & 1.00 & 4.23 & 4.35 & 4.50 & 0.53 & $<0.001$ & 0.478 & $<0.001$ & 0.002 & 0.745 & 0.950 \\
\hline & LDM & 1.00 & 5.51 & 4.56 & 3.43 & 0.53 & & & & $<0.001$ & 0.023 & 0.081 \\
\hline \multirow[t]{2}{*}{ Tollip } & GM & 1.00 & 0.57 & $1 \cdot 10$ & 0.78 & 0.14 & 0.076 & 0.094 & 0.206 & 0.050 & 0.606 & 0.064 \\
\hline & LDM & 1.00 & 0.61 & 0.93 & 0.60 & 0.14 & & & & & & \\
\hline \multirow[t]{2}{*}{ SIGIRR } & GM & 1.00 & 0.91 & 1.11 & 0.87 & 0.20 & 0.626 & 0.325 & 0.872 & 0.962 & 0.653 & 0.372 \\
\hline & LDM & 1.00 & 1.06 & 1.27 & 0.90 & 0.17 & & & & & & \\
\hline \multirow[t]{2}{*}{ ERBB2IP } & GM & 1.00 & 0.95 & 1.05 & 1.28 & 0.20 & 0.884 & 0.564 & 0.331 & 0.801 & 0.630 & 0.698 \\
\hline & LDM & 1.00 & $1 \cdot 15$ & 0.94 & 0.97 & 0.11 & & & & & & \\
\hline \multirow[t]{2}{*}{ CENTB1 } & GM & 1.00 & 2.01 & 0.34 & 0.40 & 0.52 & 0.003 & 0.175 & 0.572 & 0.074 & 0.003 & 0.004 \\
\hline & LDM & 1.00 & 2.73 & 0.84 & 0.41 & 0.27 & & & & & & \\
\hline
\end{tabular}

CONTR, non-challenged control; RP105, radioprotective 105; GM, gastrocnemius muscle; LDM, longissimus dorsi muscle; SOCS1, suppressor of cytokine signalling 1; Tollip, toll-interacting protein; SIGIRR, single Ig IL-1 R-related molecule; ERBB2IP, Erbb2-interacting protein; CENTB1, centaurin $\beta 1$.

* $P$ values were obtained using treatment as the main effect and by analysing data from the GM and LDM as repeated measures.

† The LPS pigs were compared with CONTR pigs to determine the effect of LPS. Linear and quadratic polynomial contrasts were used to determine the response to Asn supplementation among LPS-challenged pigs.

Akt and AMPK are considered to regulate protein degradation in muscle through FOXO and FOXO target genes (i.e. MAFbx and MuRF1) ${ }^{(1,18)}$. In our present experiment, LPS challenge increased phosphorylation of $\operatorname{AMPK} \alpha$, and decreased phosphorylation of Akt, which is consistent with the findings of Orellana et $a l^{(2)}$ and Frost and Lang ${ }^{(4)}$. These data indicate that injection of LPS enhanced AMPK activity but inhibited Akt activity in skeletal muscle. In the present study, consistent with decreased mRNA expression of $M A F b x$ and $M u R F 1$ in muscle, Asn supplementation to the LPS-challenged pigs decreased the phosphorylation of AMPK $\alpha$ and increased the phosphorylation of Akt and FOXO1. AMPK, in an active (phosphorylated) state, can enhance the activity of FOXO transcription factor family members, leading to muscle wasting ${ }^{(18)}$. On the contrary, the phosphorylation of Akt inhibits muscle protein degradation by phosphorylating and inactivating FOXO 
transcription factors ${ }^{(2)}$. Thus, we speculated that Asn's ability to attenuate muscle atrophy may be related to preventing LPSinduced inhibition of Akt and activation of AMPK $\alpha$ and FOXO1.

Pro-inflammatory cytokines can lead to muscle wasting directly or via alterations of Akt/FOXO/ubiquitin-proteasome pathway ${ }^{(15,42)}$. In addition, skeletal muscle metabolism is under hormonal control ${ }^{(43)}$, and many of the hormonal responses to sepsis and endotoxaemia are mediated by enhanced synthesis and secretion of pro-inflammatory cytokines ${ }^{(44)}$. In our study, LPS challenge increased the concentrations of plasma TNF- $\alpha$, cortisol and glucagon, and decreased plasma glucose concentration, and increased TNF- $\alpha$ mRNA expression in muscles. Cytokines have been shown to increase catabolic hormones such as cortisol ${ }^{(45)}$ and glucagon ${ }^{(46)}$. The metabolic effects of cortisol are enhanced with skeletal muscle protein breakdown to provide gluconeogenic substrate and amino acids for liver protein synthesis ${ }^{(45)}$. Blood glucose level, which is regulated by the balance between anabolic and catabolic (glucagon and cortisol) hormones, is related to muscle fibre composition and could partially indicate ultimate pork quality ${ }^{(47,48)}$. In the present study, Asn supplementation to the LPS-challenged pigs decreased the concentrations of TNF- $\alpha$, cortisol and glucagon in plasma, and the mRNA expression of $T N F-\alpha$ in muscles. The data support the notion that dietary Asn supplementation may attenuate muscle atrophy partially by reducing pro-inflammatory cytokines.

Activation of TLR 4 and NOD signalling pathways can induce over-production of pro-inflammatory cytokines, and elicit collateral host-tissue injury. To avoid excessive and harmful inflammatory responses, TLR4 and NOD signalling are subjected to extensive negative regulation through extracellular and intracellular mechanisms ${ }^{(49,50)}$. Of them, negative regulators of TLR4 (such as RP105, SOCS1, Tollip and SIGIRR) and NOD (such as ERBB2IP and CENTB1) play a central role in this process ${ }^{(49,50)}$. To explore the molecular mechanism(s) by which Asn reduces muscle pro-inflammatory cytokines, we examined the roles of these intracellular signalling pathways. In the present experiment, consistent with the decreased plasma and muscle TNF- $\alpha$ concentrations, Asn supplementation to the LPS-challenged pigs decreased mRNA abundance of TLR 4 and NOD signalling-related genes (TLR4, MyD88, TRAF6, NOD1, $N O D 2$ and $N F-\kappa B p 65$ ). In addition, we found that LPS challenge increased mRNA abundance of RP105, SOCS1 and CENTB1, and tended to decrease mRNA abundance of Tollip. Asn attenuated the alteration of mRNA levels of these negative regulators induced by LPS. Therefore, it is possible that the beneficial roles of Asn on muscle atrophy are closely related to reducing the expression of muscle pro-inflammatory cytokines through inhibiting the TLR4 and NOD signalling pathways via modulation of their negative regulators. We speculate that the effect of Asn on TLR4 and NOD pathways might be due to the following mechanisms. Asn can be converted to arginine and glutamine through complex metabolism ${ }^{(7)}$. Chen et $a{ }^{(51)}$ reported that arginine supplementation inhibited the excessive activation of the TLR4-MyD88 signalling pathway. In addition, Zhou et al. ${ }^{(52)}$ found that glutamine protected the intestinal tract in preterm neonatal rats with necrotising enterocolitis via reducing TLR2 and TLR4 expression. In this way, it is possible that Asn may be converted to many other amino acids to regulate the TLR 4 and NOD signalling pathways.

In summary, Asn supplementation has beneficial effects on muscle atrophy because of inhibition of muscle proteolysis via Akt activation and AMPK $\alpha$ and FOXO1 inhibition, and also decreasing the inflammatory processes via inhibition of TLR 4 and NOD signalling pathways.

\section{Acknowledgements}

The present study was supported by the National Natural Science Foundation of China (grant no. 31422053 and 31372318), and the Project of the Hubei Provincial Department of Education (grant no. T201508).

The authors' contributions are as follows: Y. L. designed the research; Y. L., X. W., S. W., D. P., W. L., H. Z., J. Z., H. S. and S. L. conducted the research; Y. L., X. W. and D. P. analysed the data; Y. L. and X. W. wrote the article; Y. L., X. L. and J. O. edited and revised the manuscript; Y. L. had primary responsibility for final content. All authors read and approved the final manuscript.

The authors declare that there are no conflicts of interest.

\section{Supplementary material}

For supplementary material/s referred to in this article, please visit http://dx.doi.org/10.1017/S000711451600297X

\section{References}

1. Fanzani A, Conraads VM, Penna F, et al. (2012) Molecular and cellular mechanisms of skeletal muscle atrophy: an update. J Cachexia Sarcopenia Muscle 3, 163-179.

2. Orellana RA, Suryawan A, Wilson FA, et al. (2012) Development aggravates the severity of skeletal muscle catabolism induced by endotoxemia in neonatal pigs. Am I Physiol Regul Integr Comp Physiol 302, R682-R690.

3. Philippou A, Maridaki M, Theos A, et al. (2012) Cytokines in muscle damage. Adv Clin Chem 58, 49-87.

4. Frost RA \& Lang CH (2008) Regulation of muscle growth by pathogen-associated molecules. J Anim Sci 86, E84-E93.

5. Zoico E \& Roubenoff R (2002) The role of cytokines in regulating protein metabolism and muscle function. Nutr Rev 60, 39-51.

6. Jamart C, Gomes AV, Dewey S, et al. (2014) Regulation of ubiquitin-proteasome and autophagy pathways after acute LPS and epoxomicin administration in mice. BMC Musculoskelet Disord 15, 166.

7. Wu G, Bazer FW, Davis TA, et al. (2007) Important roles for the arginine family of amino acids in swine nutrition and production. Livest Sci 112, 8-22.

8. Zhang J, Fan J, Venneti S, et al. (2014) Asparagine plays a critical role in regulating cellular adaptation to glutamine depletion. Mol Cell 56, 205-218.

9. Xu P, Dai XP, Graf E, et al. (2014) Effects of glutamine and asparagine on recombinant antibody production using $\mathrm{CHO}-$ GS cell lines. Biotechnol Prog 30, 1457-1468. 
10. Lancha AH Jr,, Poortmans JR \& Pereira LO (2009) The effect of 5 days of aspartate and asparagine supplementation on glucose transport activity in rat muscle. Cell Biochem Funct 27, 552-557.

11. Ahn MY, Yoon HE, Park JH, et al. (2013) Characterization of NODs and TLRs in innate immune response of human cementoblast cells. Oral Dis 19, 374-380.

12. Tamrakar AK, Schertzer JD, Chiu TT, et al. (2010) NOD2 activation induces muscle cell-autonomous innate immune responses and insulin resistance. Endocrinology 151, 5624-5637.

13. Prajapati B, Jena PK, Rajput $P$, et al. (2014) Understanding and modulating the toll like receptors (TLRs) and NOD like receptors (NLRs) cross talk in type 2 diabetes. Curr Diabetes Rev 10, 190-200.

14. Frost RA, Nystrom GJ \& Lang CH (2002) Lipopolysaccharide regulates proinflammatory cytokine expression in mouse myoblasts and skeletal muscle. Am J Physiol Regul Integr Comp Physiol 283, R698-R709.

15. Crossland $\mathrm{H}$, Constantin-Teodosiu D, Gardiner SM, et al. (2008) A potential role for Akt/FOXO signalling in both protein loss and the impairment of muscle carbohydrate oxidation during sepsis in rodent skeletal muscle. J Physiol 586, 5589-5600.

16. Steinberg GR, Michell BJ, van Denderen BJ, et al. (2006) Tumor necrosis factor alpha-induced skeletal muscle insulin resistance involves suppression of AMP-kinase signaling. Cell Metab 4, 465-474.

17. Ko HJ, Zhang Z, Jung DY, et al. (2009) Nutrient stress activates inflammation and reduces glucose metabolism by suppressing AMP-activated protein kinase in the heart. Diabetes $\mathbf{5 8}$, 2536-2546.

18. Nakashima K \& Yakabe Y (2007) AMPK activation stimulates myofibrillar protein degradation and expression of atrophyrelated ubiquitin ligases by increasing FOXO transcription factors in $\mathrm{C} 2 \mathrm{C} 12$ myotubes. Biosci Biotechnol Biochem $\mathbf{7 1}$, $1650-1656$.

19. Merrifield CA, Lewis M, Claus SP, et al. (2011) A metabolic system-wide characterisation of the pig: a model for human physiology. Mol Biosyst 7, 2577-2588.

20. Dunshea FR \& Cox ML (2008) Effect of dietary protein on body composition and insulin resistance using a pig model of the child and adolescent. Nutr Diet 65, S60-S65.

21. National Research Council (1998) Nutrient Requirements of Swine, 10th ed. Washington, DC: National Academic Press.

22. Li S, Liu YL, Shi HF, et al. (2012) Effects of asparagine on growth performance, blood cell differential count and blood biochemical indices of weaned pigs challenged with lipopolysaccharide. Chin J Anim Nutr 24, 2450-2458.

23. Liu Y, Huang J, Hou Y, et al. (2008) Dietary arginine supplementation alleviates intestinal mucosal disruption induced by Escherichia coli lipopolysaccharide in weaned pigs. Br J Nutr 100, 552-560.

24. Liu Y, Chen F, Odle J, et al. (2012) Fish oil enhances intestinal integrity and inhibits TLR4 and NOD2 signaling pathways in weaned pigs after LPS challenge. J Nutr $\mathbf{1 4 2}$, 2017-2024.

25. Drew B, Phaneuf S, Dirks A, et al. (2003) Effects of aging and caloric restriction on mitochondrial energy production in gastrocnemius muscle and heart. Am J Physiol Regul Integr Comp Physiol 284, R474-R480.

26. Ooi PT, da Costa N, Edgar J, et al. (2006) Porcine congenital splayleg is characterised by muscle fibre atrophy associated with relative rise in MAFbx and fall in P311 expression. $B M C$ Vet Res $\mathbf{2}, 23$

27. Touchette KJ, Carroll JA, Allee GL, et al. (2002) Effect of spraydried plasma and lipopolysaccharide exposure on weaned pigs: I. Effects on the immune axis of weaned pigs. I Anim Sci 80, 494-501.

28. Ewaschuk J, Endersby R, Thiel D, et al. (2007) Probiotic bacteria prevent hepatic damage and maintain colonic barrier function in a mouse model of sepsis. Hepatology $\mathbf{4 6}$, 841-850.

29. Alscher KT, Phang PT, McDonald TE, et al. (2001) Enteral feeding decreases gut apoptosis, permeability, and lung inflammation during murine endotoxemia. Am J Physiol Gastrointest Liver Physiol 281, G569-G576.

30. Xu FL, You HB, Li XH, et al. (2008) Glycine attenuates endotoxin-induced liver injury by downregulating TLR 4 signaling in Kupffer cells. Am J Surg 196, 139-148.

31. Livak KJ \& Schmittgen TD (2001) Analysis of relative gene expression data using real-time quantitative PCR and $2^{-\Delta \Delta \mathrm{CT}}$ method. Methods 25, 402-408.

32. Vary TC, Jefferson LS \& Kimball SR (1999) Amino acidinduced stimulation of translation initiation in rat skeletal muscle. Am J Physiol 277, E1077-E1086.

33. Hulmi JJ, Lockwood CM \& Stout JR (2010) Effect of protein/ essential amino acids and resistance training on skeletal muscle hypertrophy: a case for whey protein. Nutr Metab (Lond) 7, 51.

34. Sacheck JM, Ohtsuka A, McLary SC, et al. (2004) IGF-I stimulates muscle growth by suppressing protein breakdown and expression of atrophy-related ubiquitin ligases, atrogin-1 and MuRF1. Am J Physiol Endocrinol Metab 287, E591-E601.

35. Smith GI, Atherton P, Reeds DN, et al. (2011) Omega-3 polyunsaturated fatty acids augment the muscle protein anabolic response to hyperinsulinaemia-hyperaminoacidaemia in healthy young and middle-aged men and women. Clin Sci (Lond) 121, 267-278.

36. Shiota C, Abe T, Kawai N, et al. (2015) Flavones inhibit LPSinduced atrogin-1/MAFbx expression in mouse C2C12 skeletal myotubes. J Nutr Sci Vitaminol (Tokyo) 61, 188-194.

37. Jaitovich A, Angulo M, Lecuona E, et al. (2015) High $\mathrm{CO}_{2}$ levels cause skeletal muscle atrophy via AMP-activated kinase (AMPK), FoxO3a protein, and muscle-specific Ring finger protein 1 (MuRF1). $J$ Biol Chem 290, 9183-9194.

38. Dehoux MJ, van Beneden RP, Fernández-Celemín L, et al. (2003) Induction of MafBx and MuRF ubiquitin ligase mRNAs in rat skeletal muscle after LPS injection. FEBS Lett $\mathbf{5 4 4}$, 214-217.

39. Bodine SC, Latres E, Baumhueter S, et al. (2001) Identification of ubiquitin ligases required for skeletal muscle atrophy. Science 294, 1704-1708.

40. Maier T, Güell M \& Serrano L (2009) Correlation of mRNA and protein in complex biological samples. FEBS Lett 583, 3966-3973

41. Koussounadis A, Langdon SP, Um IH, et al. (2015) Relationship between differentially expressed mRNA and mRNAprotein correlations in a xenograft model system. Sci Rep $\mathbf{5}$, 10775.

42. Mann DL \& Reid MB (2003) Exercise training and skeletal muscle inflammation in chronic heart failure: feeling better about fatigue. J Am Coll Cardiol 42, 869-872.

43. Izquierdo M, Häkkinen K, Antón A, et al. (2001) Maximal strength and power, endurance performance, and serum hormones in middle-aged and elderly men. Med Sci Sports Exerc 33, 1577-1587.

44. Frost RA, Nystrom GJ, Jefferson LS, et al. (2007) Hormone, cytokine, and nutritional regulation of sepsis-induced increases in atrogin-1 and MuRF1 in skeletal muscle. Am J Physiol Endocrinol Metab 292, E501-E512. 
45. Burton D, Nicholson G \& Hall G (2004) Endocrine and metabolic response to surgery. Contin Educ Anaesth Crit Care Pain 4, 144-147.

46. Grunfeld C, Zhao C, Fuller J, et al. (1996) Endotoxin and cytokines induce expression of leptin, the ob gene product, in hamsters. J Clin Invest 97, 2152-2157.

47. Tappy L (2008) Basics in clinical nutrition: carbohydrate metabolism. Eur e-J Clin Nutr Metab 3, e192-e195.

48. Choe JH, Choi YM, Lee SH, et al. (2009) The relation of blood glucose level to muscle fiber characteristics and pork quality traits. Meat Sci $\mathbf{8 3}, 62-67$.

49. Kondo T, Kawai T \& Akira S (2012) Dissecting negative regulation of Toll-like receptor signaling. Trends Immunol 33, 449-458.
50. Coll RC \& O'Neill LA (2012) New insights into the regulation of signalling by toll-liker receptors and nod-like receptors. J Innate Immun 2, 406-421.

51. Chen Y, Chen D, Tian G, et al. (2012) Dietary arginine supplementation alleviates immune challenge induced by Salmonella enterica serovar Choleraesuis bacterin potentially through the Toll-like receptor 4-myeloid differentiation factor 88 signalling pathway in weaned piglets. BrJ Nutr $\mathbf{1 0 8}$, 1069-1076.

52. Zhou W, Li W, Zheng XH, et al. (2014) Glutamine downregulates TLR-2 and TLR- 4 expression and protects intestinal tract in preterm neonatal rats with necrotizing enterocolitis. J Pediatr Surg 49, 1057-1063. 